\title{
Esfera pública en Argentina en el Siglo XIX: Estudios, Críticas y Nuevas Aproximaciones
}

\author{
Pablo Vagliente \\ Universidad Nacional de Villa María (Argentina) \\ pablovagliente@yahoo.com
}

\begin{abstract}
Resumen
Esta comunicación procura ofrecer una visión resumida de los principales aportes generados en la historiografía argentina reciente en torno a la esfera pública política y algunos de sus temas conexos, como el desarrollo de la ciudadanía, las viejas y nuevas sociabilidades, la opinión pública o las prácticas electorales. Se sostiene asimismo que esta visión está centrada en investigaciones sobre Buenos Aires, sin que se produzca una síntesis "nacional" adecuada y necesaria.
\end{abstract}

Palabras clave: ESFERA PÚBLICA, HISTORIOGRAFÍA, ARGENTINA, SIGLO XIX.

\begin{abstract}
This article will attempt to offer a summary vision of the principle contributions by recent Argentinean historiography in reference to the sphere of public policy and some of the connected themes, such as the development of citizenship, old and new social lifestyles, public opinion and electoral practice. This article also argues that this vision is focused on research about Buenos Aires, rather than on the national level.
\end{abstract}

Key Words: SPHERE OF PUBLIC, HISTORIOGRAPHY, ARGENTINA, $19^{\text {th }}$ CENTURY 
La esfera pública como tema de la historiografía se encuentra poco desarrollado en Argentina. Aunque se lo debe asociar al tipo de cosas de las que no se podía hablar ni escribir durante la última dictadura militar argentina, que finaliza en 1983, cuando retorna la democracia no se observó un interés dominante por esta clase de problemas, probablemente por la urgencia de darle salida a otros trabajos postergados por esa interrupción institucional. Pero la más señalada historiadora argentina que ha impulsado estos estudios, Hilda Sábato, suele mencionar que uno de los grupos intelectuales de aquellos años duros, el grupo del PEHESA que funcionaba en Buenos Aires, integrado por ella, Leandro Gutiérrez, Juan Carlos Korol, Luis Alberto Romero, entre otros, se dedicó a dar los primeros pasos en torno a las preguntas y particularidades de la estructuración de una esfera pública en Argentina. Precisamente Sábato va a avanzar, a fines de los 80 y comienzos de los 90, con trabajos originales escritos en colaboración con Ema Cibotti o Elías José Palti. En esos años, pero desde un marco institucional diferente, Pilar González Bernaldo, más enmarcada en las conceptualizaciones que sobre los espacios concretos de lo público viene realizando François-Xavier Guerra ${ }^{1}$, ha dado a conocer distintas elaboraciones de los mecanismos de sociabilidad política, a partir de su ejemplar tesis doctoral, finalizada hace más de una década y que -tardía pero felizmente- vio la luz editorial al comenzar el nuevo siglo ${ }^{2}$.

Una realidad conocida en el campo historiográfico argentino -y probablemente común en otras historiografías "nacionales"- es el desbalance o desequilibrio de los trabajos realizados por historiadores que se desempeñan en instituciones con sede en la capital, en relación con los del interior del país. En las provincias, como temática emergente es propia de la última mitad de la década del 90. Un impulso particular y poco conocido le dio Carlos Forment, a través de un estudio comparativo cuya investigación se inició en Argentina en 1995, donde Buenos Aires, Santa Fe y Córdoba aparecen como las experiencias más vigorosas de la publicidad moderna ${ }^{3}$. Aunque los resultados de este trabajo están por aparecer, ya el hecho de ampliar la base de sustentación empírica de su proyecto fue una decisión plausible y fructífera. En los últimos años en Córdoba encontramos investigadores -entre los que me incluyo- cuyos estudios están dando cuenta de diversos aspectos y problemas de la esfera pública para los años 1850-1930, especialmente ${ }^{4}$.

\footnotetext{
${ }^{1}$ François-Xavier Guerra, Modernidad e independencias (Madrid: Mapfre, 1992); François-Xavier Guerra, Annick Lempérière, et al., Los espacios públicos en Iberoamérica. Ambigüedades y problemas. Siglos XVIII y XIX (México: FCE, 1998)

2 Pilar González, La creation d'une nation. Histoire politique des nouvelles appartenances culturelles dans la ville de Buenos Aires entre 1829-1862, 3 tomos (París, 1992), mimeografiado; traducción castellana Civilidad y política en los orígenes de la Nación Argentina. Las sociabilidades en Buenos Aires, 1829-1862 (Buenos Aires: FCE, 2001).

${ }^{3}$ Carlos, Forment, "Group formation in the political sphere: an interpretative approach to democratic transitions in Early Modern Spanish America" (Princeton: Princeton University, 1991), mimeografiado. Acaba de publicarse Democracy in Latin America, 1760-1900. Civic Selfhood and Public Life in Mexico and Peru, vol. 1 (Chicago: University of Chicago Press, 2003).

4 Pablo Vagliente, Construyendo la esfera pública desde el asociativismo: Córdoba 1850-1880 (Córdoba: Universidad Nacional de Córdoba, 2000); Gardenia Vidal, "El Círculo de Obreros de Córdoba (1897-1907). Algunas características del espacio público de una ciudad del interior", en Gardenia Vidal y Pablo Vagliente, comp., Por la señal de la cruz. Estudios sobre Iglesia Católica y sociedad en Córdoba, s. XVII-XX (Córdoba: Ferreyra Editor, 2002).
} 
Sin embargo, se encuentran con anterioridad conocidos trabajos sobre temas conexos a la esfera pública, como el de la prensa política -el trabajo referente es, como en muchos aspectos de la historia social y política argentina, el José Hernández y sus mundos de Tulio Halperín Donghi-, el de las asociaciones voluntarias, con especial proliferación en el subcampo de estudios inmigratorios, y los de las sociabilidades de cuño moderno ${ }^{5}$.

Si nos dejamos guiar por la clasificación de Carlos Forment sobre las distintas vertientes de los estudios neotocquevillianos en relación al desarrollo de la democracia (cada vertiente le asigna prioridad a la sociedad civil, a la sociedad política, a la sociedad económica, a la esfera pública o a los centros sociales) ${ }^{6}$, podemos aceptar que hasta ahora en Argentina el enfoque teórico predominante ha sido el propuesto por Jürgen Habermas ${ }^{7}$, abocados a indagar en una triple base conformada por la prensa escrita, las asociaciones y las movilizaciones callejeras. Además de la influencia de Habermas, se debe señalar la recepción de la obra de Maurice Agulhon, en particular en los trabajos de González Bernaldo y de Sandra Gayol; y que nuestros colegas chilenos parecen haber advertido e indagado antes que los argentinos ${ }^{8}$.

Ahora bien, es interesante valorar que los textos y las investigaciones que se han guiado por el modelo habermasiano en Argentina, padecen casi los mismos defectos que se le han marcado al sociólogo de Frankfurt'; por ejemplo, que su concepción de esfera pública descansa ante todo en la producción pública burguesa; que no toma en cuenta la participación activa de las mujeres; que no sabe comprender cómo la religión afecta decisivamente esa conformación de la esfera pública. Se podría decir, irónicamente, que se ha hecho más historia moderna que contemporánea.

En relación a los intereses empíricos sobre la esfera pública, se nota un marcado predominio de investigación sobre las distintas formas de participación en la representación política, en particular los vinculados con la historia electoral, que si bien se lo hace desde una concepción más renovadora de la historia política, deja campo fértil para intentar una mirada más integradora, en especial desde la historia sociocultural, para abordar el proceso de emergencia

\footnotetext{
${ }^{5}$ Sandra Gayol, “Ambitos de sociabilidad en Buenos Aires: despachos de bebidas y cafes, 1860-1900”, Anuario del IEHS, no. 8 (1993): 257-273; María E Argeri y Sandra Chia, "Resistiendo la ley: ámbitos peligrosos de sociabilidad y conducta social. Gobernación del Río Negro, 1880-1930", Anuario del IEHS, no. 8 (1993): 275-306.

${ }^{6}$ Carlos Forment, "Tocquevilleanos y Democracia Civil", Nexos Virtual (2002). El artículo fue bajado del portal en la web de la revista: http://www.nexos.com.mx

${ }^{7}$ Jürgen Habermas, Historia y crítica de la opinión pública. La transformación estructural de la vida pública (Barcelona: Gustavo Gili, 1997).

${ }^{8}$ Maurice Agulhon, et al., Formas de sociabilidad en Chile, 1840-1940 (Santiago de Chile: Fundación Mario Góngora, 1992); Maurice Agulhon, Pénitents et francs-maçons de l'ancienne Provence (París: Fayard, 1984); Maurice Agulhon y Mayvonne Bodiguel, Les associations au village (Le Paradou: Actes Sud, 1981); Maurice Augulhon, Historia Vagabunda (México: Instituto Mora, 1994).

${ }^{9}$ Ver, por ejemplo, Craig Calhoun, ed., Habermas and the public sphere (Massachusetts: MIT Press, 1992); Cindy Griffin, "The essencialist roots of the public sphere: a feminist critique", Western Journal of Communication 60, no. 1 (1996): 21-39.
} 
de la esfera pública. Propongo comentar ahora algunos de los trabajos principales de esa renovada historia política.

Como he mencionado, Hilda Sábato seguramente es quien más ha desarrollado este tema que estoy tratando, cuando lleva ya más de una década de trabajos que van profundizando los lineamientos de un artículo de 1992 en Past and Present. Sábato parte de la definición de esfera pública burguesa, o esfera pública política, de Habermas y lo aplica para el caso de Buenos Aires entre 1850 y 1880 . Su pregunta inicial arranca de constatar que el sufragio universal masculino aparece muy tempranamente en esa jurisdicción (en 1821), pero sin embargo esta reforma legislativa no logra implicar un avance concreto hacia la ciudadanización política; el voto no es condición suficiente ${ }^{10}$. Si en 1992 Hilda Sábato podía afirmar que "este trabajo crítico aún no se ha emprendido de manera sistemática", una década después la proliferación de estudios sobre historia electoral ha llevado a que, por ejemplo, Marcela Ternavasio vea necesario presentar ya un artículo con el indicativo subtítulo de "un balance de la historia del sufragio rioplatense" ${ }^{~} 11$. Pero, volviendo a los trabajos de Sábato, lo de ella no se limitó al estudio de los mecanismos del voto y su impacto en la esfera pública política, aún cuando ha concentrado allí sus energías empíricas. Antes bien, debe señalarse su vocación por ampliar sus análisis a buena parte del campo de la representación política del período -pero siempre limitado a la capital argentina-, es decir que también ha avanzado en la comprensión de las redes asociativas de la sociedad civil y de la cultura de la movilización, como puede advertirse en $L a$ Politica en Las Calles (1998) ${ }^{12}$.

Alberto Lettieri ha estudiado en modo permanente el tema de la opinión pública. No en el sentido que se encuentra en el trabajo citado de Guerra y Lempérière, donde el mayor interés se centra en develar la polisemia del concepto, sino más bien en situar la emergencia de ella en un contexto claro de "disciplinamiento del criterio público" y de "depuración de sus ámbitos formadores". Lettieri, a pesar de señalar que ese objetivo se alcanza mediante la imposición de lo que llama "falacia periodística" -la identidad entre opinión pública y prensa- y la "falacia institucional" -los representantes electos asumen esa identidad para sí-, parece terminar por caer él mismo en la primera de las falacias mencionadas, ya que no logra dejar demostrado que la opinión pública logra ser, antes que la opinión sostenida desde la prensa, la de los grupos subalternos movilizados "por medio de métodos clientelares tradicionales" ${ }^{13}$.

\footnotetext{
${ }^{10}$ El artículo de Past and Present fue luego traducido y publicado ese mismo año: Hilda Sábato, "Ciudadanía, participación política y la formación de una esfera pública en Buenos Aires, 1850-1880", Siglo XIX. Revista de Historia, no. 11 (1992); también apareció en Entrepasados, no. 6 (1996): 65-88.

${ }^{11}$ Marcela Ternavasio, "Elecciones y poder político. Un balance sobre el papel del sufragio en la historia política rioplatense de la primera mitad del siglo XIX", Jornadas Internacionales: La política en la Argentina del siglo XIX: nuevos enfoques e interpretaciones (Buenos Aires, 2001). De muy reciente aparición, ésta y otras ponencias del encuentro han aparecido en Hilda Sábato y Alberto Lettieri, comp., La vida política en la Argentina del siglo XIX. Armas, votos y voces (Buenos Aires: FCE, 2003).

${ }^{12}$ Hilda Sábato, La politica en las calles. Entre el voto y la movilización, Buenos Aires, 1862-1880 (Buenos Aires: Sudamericana, 1998).

${ }^{13}$ Alberto Lettieri, "Formación y disciplinamiento de la opinión pública en los inicios del sistema político moderno. Argentina, 1862-1868", Entrepasados, no. 6 (1994): 33-48.
} 
Recientemente González Bernaldo ha ofrecido una explicación plausible para lo que parece constituir una "contradicción aparente de la vida política porteña: la fuerte politización de la vida pública y la baja participación e indiferencia hacia el escrutinio". Para ella, son las asociaciones políticas que conocemos como clubes -los antecedentes de los partidos políticos propiamente dichos- la variable explicativa del problema, puesto que éstos se habrían constituido en una primera instancia representativa (la confección de las listas de candidatos), mucho más politizada y movilizadora que la segunda instancia, formal, el día de la votación misma. Lo que me gustaría destacar es que esta visión de González Bernaldo rescata la capacidad de articular viejas redes de estructura comunitaria con nuevas redes de estructura moderna, uniendo lazos clientelares. Pero señala algo más, fundamental para aceptar una visión no reduccionista, por elitista, de la política del período: que la movilización popular, formando parte del proceso electoral, "es un mecanismo que permite integrar a un importante sector de la población para el que la representación no pasa por la concertación de listas, sino por la manifestación de una fuerza de combate", esto es, la típica violencia que suele acompañar las jornadas electorales ${ }^{14}$.

¿Cuándo surge la esfera pública, situándonos en el siglo XIX (al que desde el punto de vista político y social podríamos periodizar entre 1808 y 1912, es decir, entre el proceso de politización de la capital tras la militarización desencadenada ante las invasiones inglesas de 1806 y 1807, y la sanción de la ley Sáenz Peña de voto masculino universal, obligatorio y secreto, que rompió la hegemonía conservadora liberal)? Para el caso argentino indefectiblemente debemos situarnos en la segunda mitad del siglo XIX ${ }^{15}$, cuando cae Rosas y su régimen, caracterizado por Marcela Ternavasio como un "régimen de unanimidad", respetuoso sin embargo del cumplimiento formal del sufragio como agente legitimador -y, como lo ha mostrado Jorge Myers, productor de un discurso que recoge elementos retóricos republicanos- ${ }^{16}$, pero completamente antiliberal en tanto supresor de voces opositoras y, por ende, de la competencia electoral, por restrictiva que fuera. Es evidente que no podemos hablar de una esfera de debate público pluralista, sostenido por argumentos racionales por parte de un público activo y confrontativo, durante la intensa y extensa gestión del rosismo en Buenos Aires y en el Interior que logra controlar. Por eso el recuperado punto de partida de un proceso de conformación de una esfera pública como espacio de mediación de la sociedad civil, entre el Estado y el sector privado (espacio no exento de dificultades teóricas en la formulación

\footnotetext{
${ }^{14}$ Pilar González, "Los clubes electorales durante la secesión del Estado de Buenos Aires (1852-1861): La articulación de dos lógicas de representación política en el seno de la esfera pública porteña", en Hilda Sábato, coord., Ciudadanía politica y formación de las naciones. Perspectivas históricas de América Latina (México: FCE, 1998): $142-161$

${ }^{15}$ En ese sentido, la gestión del liberal Bernardino Rivadavia (tanto como gobernador de Buenos Aires como luego en la fallida experiencia constitucional "nacional", ambos en la década de 1820), no sólo no pudo generalizarse al conjunto de provincias interiores sino que no logró consagrar en el mismo territorio bonaerense la libertad asociativa en el plano jurídico, algo imprescindible para una esfera pública.

${ }^{16}$ Jorge Myers, Orden y virtud: El discurso republicano en el régimen rosista (Buenos Aires: Universidad Nacional de Quilmes, 1995).
} 
habermasiana, como lo ha demostrado Margaret Somers ${ }^{17}$ debe apelar a ese trípode formado por i) una prensa plural, ii) redes asociativas de muy diverso tipo y finalidad y iii) amplias movilizaciones populares. ¿Por qué digo recuperado punto de partida? En tanto no comienza ex nihilo: la tradición de Mayo, las experiencias acumuladas entre 1810 y 1835, e incluso la acción crítica disidente y en el exilio entre 1835 y 1852, pesan y se hacen presentes cuando nos situamos en la etapa post-Caseros.

A este triple asentamiento de la esfera pública hay que agregarle, sin duda, la cuarta pata de la mesa: las nuevas y viejas sociabilidades, harto presentes en la calle y en la vida pública por ende. Además del aporte de González Bernaldo, un nuevo libro fuerte sobre la sociabilidad también se presenta para Buenos Aires, y es el que ofrece Sandra Gayol. A partir de un concepto agulhoniano de sociabilidad como "contactos, relaciones, encuentros, intercambios cara a cara y directos gestados entre dos o más personas", Gayol aborda un mundo mucho más vívido de lo popular que el que logramos ver en la historia electoral. También es cierto que su orientación más antropológica de los temas que revisa -el auge de los cafés urbanos en la última mitad del siglo XIX, así como los despachos de bebida donde se discute, se juega, se ríe, se enfrentan los hombres; la cuestión del honor, modelando la conducta social- no nos permite una conexión directa con los desarrollos que estamos comentando sobre esfera pública política, como, en cambio, podemos conseguir en el texto de Ricardo Salvatore sobre las representaciones republicanas subyacentes en el despliegue festivo del régimen rosista ${ }^{18}$.

Hasta aquí hemos venido hablando de la forma en que se visualiza la esfera pública política porteña. ¿Alcanza ese cúmulo de investigaciones para dar cuenta de lo que sucede en el resto del país? La respuesta, negativa, tiene que ver con las falencias mismas de una historiografía que se pretende nacional pero es fuertemente porteñocentrista. Queda por plantearse las causas de la ineficacia o el desinterés demostrado por los grupos de historiadores que trabajan en las Universidades del interior del país (Córdoba, Rosario, Comahue, Jujuy, Salta, Mendoza, etcétera) por generar una sustentable historia regional (o historias regionales) que logre articular un relato que a esta altura de la función podría ser ya más "representativamente" federal.

Para situar, a modo de ejemplo, cómo un elemento no tenido demasiado en cuenta por las obras que he comentado aquí para Buenos Aires termina por configurar una esfera pública con marcadas diferencias, tomaré el tema de la influencia de la religión católica en Córdoba. Tanto en las investigaciones de Gardenia Vidal sobre el espacio público en las primeras décadas del s.

\footnotetext{
${ }^{17}$ Margaret Somers, “¿Qué hay de político o de cultural en la cultura política y en la esfera pública? Hacia una sociología histórica de la formación de conceptos", Zona Abierta, no. 77/78 (1996/97): 31-93; "Narrando y naturalizando la sociedad civil y la teoría de la ciudadanía: el lugar de la cultura política y de la esfera pública", Zona Abierta, no. 77/78 (1996/97): 255-337.

${ }^{18}$ Sandra Gayol, Sociabilidad en Buenos Aires. Hombres, honor y cafés, 1862-1910 (Buenos Aires: Ediciones del Signo, 2000); Ricardo Salvatore, "Fiestas federales: representaciones de la República en el Buenos Aires rosista", Entrepasados, no. 11, (1996).
} 
$\mathrm{XX}^{19}$, las de Silvia Roitenburd sobre el nacionalismo católico cordobés ${ }^{20}$ y las mías sobre cofradías y asociaciones católicas modernas, el catolicismo aparece como una fuerza muy viva, marcadamente defensiva ante los embates del liberalismo laicista del último tercio del siglo XIX, pero, de manera casi simultánea, desplegando estrategias agresivas de recuperación de la iniciativa pública, tanto en el terreno propiamente litúrgico-religioso como en el de las iniciativas legislativas, el plan de estudios de las escuelas o las fiestas populares, por citar algunos, lo que nos lleva a invalidar la visión de una esfera pública política de la mano confiada de un liberalismo triunfante. Es posible que el caso de Córdoba, más que el de Buenos Aires, sea indicativo de una tendencia o vertiente más generalizada en el interior del país, aunque falta demostrar esto todavía.

A modo de conclusión en estas notas historiográficas, es evidente que la historia de la esfera pública ha tenido ya aportes sustantivos que, a su vez, han alimentado una renovación de la historia política, social y cultural. En estos pasos dados con fuerza en la década del 90, desde marcos teóricos claramente definidos, se siente, una vez más, la ausencia de vigorosas historias regionales que contribuyan a dar una imagen más completa y compleja de las dinámicas argentinas. En tal sentido, la convocatoria de ámbitos académicos específicos para el tratamiento comparativo de la esfera pública argentina puede arrojar resultados prometedores, que permitan avizorar una síntesis ahora sí enriquecida.

\section{Bibliografía}

Agulhon, Maurice. Pénitents et francs-maçons de l'ancienne Provence. París: Fayard, 1992. . Historia Vagabunda. México: Instituto Mora, 1994.

Agulhon, Maurice, et al. Formas de sociabilidad en Chile, 1840-1940. Santiago de Chile: Fundación Mario Góngora, 1992.

Agulhon, Maurice y Mayvonne Bodiguel. Les associations au village. Le Paradou: Actes Sud, 1981.

Argeri, María E. y Sandra Chia. "Resistiendo la ley: ámbitos peligrosos de sociabilidad y conducta social. Gobernación del Río Negro, 1880-1930". Anuario del IEHS, no. 8 (1993): 275-306.

Calhoun, Craig, ed. Habermas and the public sphere. Massachusetts: MIT Press, 1992.

Forment, Carlos. "Group formation in the political sphere: an interpretative approach to democratic transitions in Early Modern Spanish America". Mimeografiado. Princeton: Princeton University, 1992.

“Tocquevilleanos y Democracia Civil”, Nexos Virtual (2000).

\footnotetext{
${ }^{19}$ Gardenia Vidal "Reacción de la 'Tradición' y sus intentos de formar un Partido Católico. Córdoba 1918-1925”, en María Estela Spinelli, et al. comp., La conformación de las identidades políticas en la Argentina del siglo XX (Córdoba: UNC-UNCE-UNMP, 1999): 83-109.

${ }^{20}$ Silvia Roitenburd, El Nacionalismo Católico Cordobés (Córdoba: Ferreyra Editor, 2000).
} 
. Democracy in Latin America, 1760-1900. Civic Selfhood and Public Life in Mexico and Peru. Vol. 1. Chicago: University of Chicago Press, 2003.

Gayol, Sandra. "Ambitos de sociabilidad en Buenos Aires: despachos de bebidas y cafés, 1860 1900". Anuario del IEHS, no. 8 (1993): 257-273.

Sociabilidad en Buenos Aires. Hombres, honor y cafés, 1862-1910. Buenos Aires: Ediciones del Signo, 2000.

González, Pilar. La creation d'une nation. Histoire politique des nouvelles appartenances culturelles dans la ville de Buenos Aires entre 1829 -1862. 3 tomos. Mimeografiado. París, 1992. (Traducción castellana: Civilidad y politica en los orígenes de la Nación Argentina. Las sociabilidades en Buenos Aires, 1829-1862. Buenos Aires: FCE, 2001.

"Los clubes electorales durante la secesión del Estado de Buenos Aires (1852-1861): La articulación de dos lógicas de representación política en el seno de la esfera pública porteña”. En Ciudadanía política y formación de las naciones. Perspectivas históricas de América Latina, Hilda Sábato, coord. México: FCE, 1998: 142-161.

Griffin, Cindy. "The essencialist roots of the public sphere: a feminist critique". Western Journal of Communication 60, no. 1 (1992): 21-39.

Guerra, François-Xavier. Modernidad e independencias. Madrid: Mapfre, 1992.

Guerra, François-Xavier, Annick Lempérière, et al. Los espacios públicos en Iberoamérica. Ambigüedades y problemas. Siglos XVIII y XIX. México: FCE, 1998.

Habermas, Jürgen. Historia y crítica de la opinión pública. La transformación estructural de la vida pública. Barcelona: Gustavo Gili, 2000.

Lettieri, Alberto. "Formación y disciplinamiento de la opinión pública en los inicios del sistema político moderno. Argentina, 1862-1868". Entrepasados, no. 6, (1998): 33-48.

Myers, Jorge. Orden y virtud: El discurso republicano en el régimen rosista. Buenos Aires: Universidad Nacional de Quilmes, 1995.

Roitenburd, Silvia. El Nacionalismo Católico Cordobés. Córdoba: Ferreyra Editor, 2000.

Sábato, Hilda. "Ciudadanía, participación política y la formación de una esfera pública en Buenos Aires, 1850-1880". Siglo XIX. Revista de Historia, no. 11, (1992).

La política en las calles. Entre el voto y la movilización, Buenos Aires, 1862-1880. Buenos Aires: Sudamericana, 1998.

Salvatore, Ricardo. "Fiestas federales: representaciones de la República en el Buenos Aires rosista", Entrepasados, no. 11 (1996).

Somers, Margaret. "¿Qué hay de político o de cultural en la cultura política y en la esfera pública? Hacia una sociología histórica de la formación de conceptos". Zona Abierta, no. 77/78 (1996/97): 31-93.

"Narrando y naturalizando la sociedad civil y la teoría de la ciudadanía: el lugar de la cultura política y de la esfera pública". Zona Abierta, no. 77/78 (1996/97): 255-337.

Ternavasio, Marcela. "Elecciones y poder político. Un balance sobre el papel del sufragio en la historia política rioplatense de la primera mitad del siglo XIX”. En La vida política en la Argentina del s. XIX. Armas, votos y voces, Hilda Sábato y Alberto Lettieri, comp. Buenos Aires: FCE, 2003.

Vagliente, Pablo. Construyendo la esfera pública desde el asociativismo: Córdoba 1850-1880. Córdoba: Universidad Nacional de Córdoba, 2000. 
Vidal, Gardenia. "Reacción de la 'Tradición' y sus intentos de formar un Partido Católico. Córdoba 1918-1925". En La conformación de las identidades políticas en la Argentina del siglo XX. María Estela Spinelli, et al. comp. Córdoba: UNC-UNCE-UNMP, 1999: 83-109.

"El Círculo de Obreros de Córdoba (1897-1907). Algunas características del espacio público de una ciudad del interior". En Por la señal de la cruz. Estudios sobre Iglesia Católica y sociedad en Córdoba, s. XVII-XX. Gardenia Vidal y Pablo Vagliente, comp. Córdoba: Ferreyra Editor, 2002.

Fecha de recepción del artículo: 14 de mayo de 2003

Fecha de aceptación: 22 de agosto de 2003 